\title{
THE
}

2018

\section{Slow and deliberate cooperation in the commons}

\author{
Chris Brozyna \\ University of Rhode Island \\ Todd Guilfoos \\ University of Rhode Island, guilfoos@uri.edu \\ Stephen Atlas \\ University of Rhode Island
}

Follow this and additional works at: https://digitalcommons.uri.edu/enre_facpubs

The University of Rhode Island Faculty have made this article openly available.

Please let us know how Open Access to this research benefits you.

This is a pre-publication author manuscript of the final, published article.

Terms of Use

This article is made available under the terms and conditions applicable towards Open Access Policy Articles, as set forth in our Terms of Use.

\section{Citation/Publisher Attribution}

Brozyna, C., Guilfoos, T., \& Atlas, A. (2018). Slow and deliberate cooperation in the commons. Nature Sustainability, 1, 184-189. doi: 10.1038/s41893-018-0050-z

Available at: https://doi.org/10.1038/s41893-018-0050-z

This Article is brought to you for free and open access by the Environmental and Natural Resource Economics at DigitalCommons@URI. It has been accepted for inclusion in Environmental and Natural Resource Economics Faculty Publications by an authorized administrator of DigitalCommons@URI. For more information, please contact digitalcommons-group@uri.edu. 
8 ' Marketing, University of Rhode Island, Kingston, RI 02881;

13 Keywords:

14 Behavioural Economics, Cognitive Scarcities, Common Pool Resource Management, 15 Sustainability

\section{Slow and Deliberate Cooperation in the Commons}

16 
18 We test how fast and slow thought processes affect cooperation for sustainability by manipulating time pressure in a dynamic common pool resource experiment. Sustainable management of shared resources critically depends on decisions in the current period to leave enough stock so that future generations are able to draw upon the remaining limited natural resources. An intertemporal common pool resource game represents a typical dynamic for social dilemmas involving natural resources. Using one such game, we analyse decisions throughout time. We find that people in this context deplete the common resource to a greater extent under time pressure, which leads to greater likelihood of stock collapse. Preventing resource collapse while managing natural resources requires actively creating decision environments that facilitate the cognitive capacity needed to support sustainable cooperation.

Overextraction of natural resources in the present can lead to negative consequences for society and is at odds with most definitions of sustainable development (1). According to Pearson (2), "the core of the idea of sustainability is the concept that current decisions should not damage prospects for maintaining or improving living standards in the future." Essential for sustainability and important to many aspects of human and animal behaviour (3-6) is cooperation. Societies with imperfect, incomplete, and shared property rights face social dilemmas characterized by conflict between individual and collective interests. Cooperative solutions in social dilemmas require individuals to overcome selfish myopic incentives to achieve better social outcomes. Across many social dilemmas, myopic resource use often yields immediate, tangible, and easy to understand benefits; while long-term cooperative and sustainable stewardship of the resource involves more thought, planning, and coordination, along with benefits that are less certain and harder to calculate (7). Understanding how cognitive pressures influence common pool resource (CPR) outcomes is vital for designing interventions to prevent resource collapse and support sustainable collective decision processes.

Effective stewardship of the commons requires understanding how institutions and cognitive factors contribute to cooperation. An expansive literature considers which institutions can establish cooperation in CPRs and why these institutions work (8-12). While institutions have been rigorously explored in relation to CPRs, less is known about what cognitive factors and decision environments produce sustainable cooperation in CPRs. One particularly salient 48 question is: do fast (intuitive) or slow (deliberative) thought processes better support sustainable 49 use of a common pool resource? We find experimental evidence that groups drawing on a 50 common pool resource are less likely to cooperate under time pressure. Instead, a slower, more 
51 deliberative, decision process supports cooperation which extends the life of the common pool 52 resource and improves social welfare.

53 Our experiment uses time pressure manipulation on an intertemporal CPR. While much

54 of the previous experimental work on social dilemmas and cognition has focused on one-shot 55 games, natural resources are often characterized as stock variables (ex. wetlands, fisheries, groundwater) which are not independent of human behaviour in previous periods. These natural assets also cannot be easily regenerated if collapse occurs. By tracking a stock of resources in our experiment we can evaluate when group behaviour causes collapse of the resource which is paramount in understanding sustainable development, the reconciliation of society's goals and the limits of the earth's natural resources $(13,14)$. We have found only one other intertemporal experiment using time pressure which examines intertemporal preferences (15) and no previous experiments involving intertemporal social dilemmas and cognitive manipulations, such as time pressure. The dynamic CPR game we employ allows us to determine how cognitive scarcity, that is present in each decision time frame, impacts the depletion and survival of shared stocks over time. Our experiment further tests whether fast and slow thought processes behave similarly in dynamic CPRs to one-shot social dilemmas.

Common pool resource decisions - and resource decisions in general - are frequently made by individuals who face cognitive constraints. For example, the condition of poverty inhibits farmers' ability to make good decisions due to cognitive resources being consumed by financial concerns, an equivalent of losing 13 IQ points (16). Risks from the natural system, such as weather variability and droughts, also tax mental resources (17). Recent research suggests that scarcities of time and money focus our cognitive system on these particular scarcities, leaving little cognitive bandwidth left to solve other problems (18-20). This may make an escape from 74 poverty more difficult, as the condition of poverty causes poor communities to heavily discount 75 future consequences of extraction behaviour: cognitive scarcities contribute to poverty traps (21). 76 One efficient strategy when faced with cognitive constraints is to apply heuristics, fast and 77 simple rules, which simplify the decision environment. These strategies adopted by subjects in 78 dynamic CPRs under limited cognitive resources could have important implications to the 79 sustainability of natural resources.

80 It is common for experimenters to use time pressure to shine a light on the innate thought 81 processes of individuals. As a cognitive constraint, time pressure is used to distinguish between 
82 fast instinctive strategies and slow deliberative strategies in the dual process theory of cognition 83 (22-26). Through applying time pressure to participants' decisions we can determine if fast, 84 instinctive strategies are more sustainable than slow, deliberative ones.

85 There are two types of cooperation in a game theoretic setting: pure cooperation, which is 86 cooperation when defection strictly maximizes payoffs (ex. one-shot social dilemma games), and 87 strategic cooperation, which is cooperation that can be long-run payoff maximizing (ex. 88 coordination games). Previous studies find evidence of increased cooperation under time 89 pressure in one-shot social dilemmas (27-30). This increased cooperation can be explained by a 90 dual process theory of cognition called the Social Heuristics Hypothesis (SHH) (5,6,31). SHH 91 predicts that deliberation can undermine pure cooperation but may support strategic cooperation 92 if the context is sensitive for intuitive thought processes (31,32). A recent meta-study (30) finds 93 evidence for the prediction of increased cooperation in social dilemmas when people rely more 94 on intuitive thought processes and finds no effects on cooperation of cognitive manipulation (ex. 95 time pressure or cognitive load) in games with the potential of future benefits. Though, there is a 96 recent study finding decreased cooperation under time pressure which is attributed to confusion 97 (33). According to $\mathrm{SHH}$, deliberation would either have no effect or increase cooperation in our 98 setting because cooperation can be payoff maximizing over the life of the common pool 99 resource, similar to a coordination game. Since none of the time pressure studies to date include 100 intertemporal games our experiment adds new evidence of cooperative behaviour of individuals 101 subjected to cognitive scarcities.

102 Utilizing a between-subject comparison test (between participants under time pressure 103 and participants without a time constraint) we find participants behave more myopically when

104 limited by time constraints, which is consistent with SHH. Thus, common pool resources have a 105 higher probability of failure when managed by people under cognitive scarcities, a finding which 106 contrasts the findings from previous time pressure experiments. We explore three potential 107 reasons for this result which include: errors in judgment $(34,35)$, slow adjustment of extraction 108 strategies during the game (36), and intuitive heuristics for myopic extraction $(5,6,31)$. Our 109 results highlight the benefits of examining intertemporal dynamics over one-shot games to 110 understand how cognition and cooperation unfolds to promote sustainable development.

\section{Dynamic CPR Model}


113 There are numerous economic experiments with dynamic CPRs that investigate different 114 institutions which propagate cooperation $(37,38)$. Our experiment uses a dynamic CPR model 115 used by Kimbrough and Vostroknutov (39). This model considers an inexhaustible private 116 resource and an exhaustible shared resource. Socially optimal resource exploitation in this game 117 requires drawing heavily from the shared resource early and preserving it as time passes. In each 118 period, $n$ players simultaneously remove tokens from an inexhaustible private account and a 119 shared exhaustible group account with the constraint that only 60 tokens in total can be taken in a 120 period. Tokens from the group account are worth twice as much as tokens from the individual 121 account. Each group member $i$ chooses the number of tokens to extract, $e_{i t}$, from the group 122 account at time $t$. The sum of the group members extraction is $E_{t}=\sum_{i=1}^{n} e_{i t}$. The group account 123 acts as the stock of a common pool resource in the experiment and the private account acts as the 124 opportunity cost of extraction.

125 The group account replenishes at a rate, $\beta$, each period, multiplied by the difference 126 between the remaining group account balance and a maximum size of the group account, $\bar{w}$. 127 Thus the group account, $w_{t}$, evolves over time according to the following formula: $w_{t}=w_{t-1}-$ $128 E_{t-1}+\beta\left(\bar{w}-w_{t-1}-E_{t-1}\right)$. The size of the group account in the present period directly 129 depends on the size of the group account in the past round and the decisions made by group 130 members in that round. To realize regrowth of the group account, groups must maintain a group 131 account level above a threshold, $\tau$. Whenever the group account is reduced below this threshold 132 there ceases to be any regrowth in the group account and the resource collapses. In our 133 experiment $\beta$ was set at 0.25 , the minimum threshold, $\tau$, was set equal to 30 tokens, and $\bar{w}$ was 134 set to 360 tokens.

135 We parameterize a relatively small regrowth rate in our experiment so that the 136 symmetrical Subgame Perfect Nash Equilibrium (SPNE) is to exhaust the resource as fast as 137 possible though gains for the group can be higher if they do not exhaust the resource. The 138 socially optimal strategy in this game is to maintain the group account indefinitely to prevent the 139 collapse of the group account. The path of the socially optimal extraction depends on the 140 parameters of the experiment and consists of a set of group account dependent choice rules, 141 detailed in the Methods section.

142 This model describes situations where societies discover a virgin resource, extract much 143 of it, and then attempt to jointly conserve the remaining resource. The presence of a threshold, 
144 below which the stock will not regenerate, is also a pillar of ecological theory (40) and is

145 descriptive of many real-world common pool resource dilemmas.

\section{Results}

Figure 1 shows the evolution of the average group account (stock) size for time pressure and non-time pressure groups. The lower stock path of time pressure groups indicates greater extraction and lower survival rates of group accounts in the time pressure treatments as compared to those under no time pressure. This suggests that time pressure leads to less cooperation and shorter survival of the common resource.

We use a Cox proportional hazard model to estimate the treatment effect of time pressure on the probability of failure of the group account. This method of survival analysis is commonly employed in medical research to measure causal effects on the probability of an event, such as death or relapse, and in economics and political science to evaluate duration data (41-44). The model is appropriate to analyse the event of failure of the group account in our experiment since the timing of collapse is a type of duration data.

Analysis at the individual level in Table 1 suggests an effect from the imposition of time pressure (group level analysis is provided in Supplementary Table 1). We find that individuals

162 exposed to time pressure face an increased rate of failure of $101.3 \%\left(2.013=e^{0.700}, p<0.01\right)$

163 over the control group in Table 1, column 2. This is sometimes referred to as the hazard ratio in 164 survival analysis studies. A similar pattern is present for individual differences in Cognitive 165 Reflection Test (CRT). An increase in correctly answered CRT questions reduced the rate of 166 group account failure by $79 \%(\mathrm{p}<0.05)$. The coefficient on the percentage of CRT questions 167 answered correctly indicates that participants who do not repress their intuitive thought process 168 induce a greater probability of failure of the group account. This finding is also consistent with 169 the average treatment effects of time pressure. The rate of increase in hazard ratio is roughly 170 equivalent across time periods with the difference in hazard ratios being proportional, which is 171 an important assumption in the Cox proportional hazards model. The results suggest that time 172 pressure significantly increases the failure rate of the group account in the intertemporal CPR 173 game which adds a different finding from much of the existing literature on cooperation and 174 intuitive decisions in one-shot social dilemmas. 
177 We also explain the effect of time pressure on the deviation of observed extraction from the 178 optimal extraction behaviour (Socially Optimal Extraction-Observed Extraction). We

179 analyse this difference in extraction behaviour because the socially optimal extraction path is 180 group account dependent and incorporates the level of the group account as a decision making 181 variable that is nonlinearly related to extraction decisions. Using a simpler extraction measure, 182 like the number of group tokens extracted, may be misleading as participants adjust to changing 183 group account levels across rounds of the game. In the following analysis we only include rounds 184 of the game before exhaustion of the group account since the observed behaviour after 185 exhaustion is trivial.

186 In Table 2 we find that time pressure induces greater extraction of the resource. A 187 negative coefficient indicates the variable increases extraction relative to the social optimal, 188 which in turn would increase the relative risk of collapse of the resource. The treatment effect is 189 statistically weak without any controls, which suggests the time within game is important to the 190 size of the treatment effect. As a robustness check, the SI reports results including subjects and 191 groups who violated the time limit to test whether results are explained by systematic differences

192 between the participants who meet the time constraint versus those who do not (Supplementary 193 Table 3). In some one-shot games there is a loss of support for intuitive cooperation when 194 including these participants. We find attenuated estimates of our treatment effect with the 195 inclusion of subjects who violate the time limit. We also take a further look at round differences 196 in Supplementary Table 4. The coefficient on time pressure is negative though the coefficient on 197 CRT score is not statistically significant. Combined with our survival analyses (Table 1) and 198 Supplementary Tables 2, 3, and 4, this gives us some confidence that the cognitive scarcities in 199 the dynamic common pool resource game induce less cooperative behaviour and increase the 200 risk of group account failure through greater myopic extraction.

\section{Discussion}

203 Our results indicate one domain in which intuitive judgment under limited cognitive 204 resources leads to more myopic behaviour, to the detriment of the individual and group welfare. 205 We find in an intertemporal social dilemma game, participants with cognitive scarcities have a 
206 propensity to extract more from a shared resource stock. This result provides empirical evidence 207 of when individuals are deliberatively cooperative, which has previously drawn almost 208 exclusively on static social dilemma experiments $(5,27,28)$. In an intertemporal setting, 209 individuals require the cognitive bandwidth for sustainable management of the resource, and 210 deliberation supports cooperation in this setting.

211 Since many common pool resource situations are intertemporal in nature, our results are 212 more germane to these contexts than those of traditional one-shot games $(27,28)$. Such one-shot 213 games are limited in their ability to capture the development of intertemporal dynamics, which 214 can have large impacts on sustainable development. In one-shot games the logical action is to 215 extract as much as possible. However, in intertemporal games with repeated interactions 216 cooperating in maintaining the resource becomes a more viable strategy (45); a phenomenon 217 which helps explain the success of some common pool resource management programs (46). So 218 it is interesting that the imposition of time pressure decreases the probability of survival of group 219 accounts in our experiment, which suggests these CPR success stories were in spite of intuitively 220 myopic behaviour.

221 We explore three potential reasons for the contrast between our results and those of prior 222 static non-cooperative games. The first possibility is that people make more mistakes when 223 confronted with a difficult problem under time pressure $(34,35)$. Such stochastic mistakes may 224 increase the variance in play from participants and the group account may be inadvertently 225 exhausted. To evaluate the variation in extraction behaviour we compare the absolute value of 226 the deviation of extraction decisions between rounds (Absolute Deviation $=\left|e_{i, t}-e_{i, t-1}\right|$ ) in 227 Supplementary Figure 1. A greater value of the absolute deviation from the time pressure 228 treatment would indicate that stochastic behaviour, or random mistakes, may play some role in 229 additional failure of groups in the survival analysis. Our results suggest that stochasticity in 230 choice is similar between time pressure treatments. This however does not suggest that other 231 mean shifting errors in extraction do not exist.

232 A second explanation for the departure from past one-shot game results is that the design 233 of the game encourages large extraction decisions at the beginning of the game and cooperation 234 requires restraining extraction behaviour once the group account nears the threshold for failure. 235 The initial extraction behaviour could induce inertia in participants under time pressure leading 236 to a slower adaptation to optimal levels of extraction. Alós-Ferrer et al. (36) found that inertia as 
237 an automatic process conflicts with a more rational deliberative one, consistent with the dual 238 process view of decision making. We can use the change in extraction behaviour to analyse 239 inertia as well as variance in individual extraction behaviour. A smaller absolute value of the 240 difference in extraction decisions indicates greater inertia in extraction decisions. We find no 241 difference in inertia between time pressure treatments, which puts serious doubts on inertia as an 242 explanation for increased extraction and greater failure of CPRs (Supplementary Figure 1).

243 A third explanation, the main hypothesis for interpretation of these results, is that the 244 dynamic aspect of the game affects intuitive cooperation among subjects. The data from our 245 experiment supports the proposition of quick and fast myopic behaviour in the commons. Our 246 finding is consistent with the $\mathrm{SHH}(5,6)$, wherein deliberation can sometimes increase 247 cooperation in settings where cooperating can be a long run payoff-maximizing strategy. Such an 248 increase in cooperation can be favored by natural selection or learning - and thus is expected to 249 occur - if cooperation is typically long-run advantageous and intuition is sufficiently sensitive to 250 context (31), or if most interactions are one-shot and the distribution of deliberation 251 costs satisfies certain conditions (32). Deliberation promotes cooperation when it leads people to 252 attend to the features of the dynamic CPR which realize cooperation as a more efficient 253 strategy. If people only really confront the nature of the collapsing resource when they have 254 time, deliberation would override myopic impulses.

255 Many decisions in our society can be characterized as dynamic choices under cognitive 256 scarcities. Our research provides insights into instinctive human behaviour, enabling us to shed 257 light on whether humans behave more myopically under temporally dynamic common pool 258 resource scenarios with quick and fast decision processes. This may well mean that cooperation 259 in the commons is more difficult to sustain because of intuitively myopic behaviour and the use 260 of policy tools becomes even more important to combat over-extraction in the commons. It is 261 also unclear how to provide the cognitive bandwidth necessary to support cooperative behaviour 262 since it can be presented through a combination of factors, though efforts to mitigate these 263 stressors for individuals operating in a common pool resource context could provide an 264 important support tool to sustainable collective management.

265 The results also highlight the implications of generalizing results of one-shot games to 266 situations that involve intertemporal trade-offs, or repeat interactions, when considering 267 sustainability. One-shot games are poor substitutes for dynamic games when exploring cognitive 
processes of human behaviour and sustainability. To evaluate the importance of deliberation in

269 thought processes to cooperation in common pool resources more aspects of these games need to 270 be explored. Specifically, there is a need to investigate how group size, uncertainty in natural 271 systems, and institutions affect the cognitive thought processes and cooperation to support 272 sustainable management.

\section{Methods}

\section{Data}

277 A total of 120 undergraduate students were recruited at a public university in the northeastern 278 United States and paid based on their performance in the game. Participants played three cycles 279 of the intertemporal CPR game in the Spring and Fall of 2016, a cycle is one set of rounds of the 280 same CPR game with the same group. In each cycle, a participant extracted tokens from a group 281 account shared with 3 other anonymous participants (a representative decision screen is shown in 282 Supplementary Figure 4). The last round (decision period) in each game was randomly 283 predetermined and not communicated to the participants to avoid last round effects. Participants 284 were randomly and anonymously regrouped after each cycle into a new group.

Participants received a show-up fee of $\$ 10$ and the average payout at the end of the game 287 yielding a return of 0.8 cents while the tokens taken from the public account yielded 1.6 cents 288 each. The economic experiment software Z-tree (47) was used to run the experiment. There were 289 three cycles in the experiment with a predetermined fixed length; the first cycle lasted 12 rounds, 290 the second cycle lasted 15 rounds, and the third cycle lasted 8 rounds. Participants were not told 291 how many rounds to expect or that there would be multiple cycles during the experiment.

292 Prior to the game, participants answered a three question Cognitive Reflection Test 293 (CRT) (shown in Supplementary Figure 3) under a 90 second time constraint (48). The Cognitive 294 Reflection Test can determine whether participants can suppress an intuitive answer which uses 295 little conscious deliberation ("System 1" spontaneous, intuitive thinking) and employ a slower 296 and more reflective cognitive process ("System 2" processes requiring mental effort and 297 reasoning) when making decisions. If a subject did not answer all three of the CRT questions 
298 before the end of the 90 seconds then they were recorded as having not finished the CRT and as 299 having answered none of the questions correct.

300 In addition to the CRT, participants answered demographic questions (as shown in 301 Supplementary Figure 2). Next participants were given instructions about the dynamic CPR 302 game (a representative copy of these instructions is provided in the Supplementary Information).

303 The experimenter read the instructions to the participants, who were required to correctly answer 3043 comprehension questions to confirm their understanding of the game. Experience with other 305 economic experiments, time to complete the comprehension questions, CRT scores, gender 306 ratios, and areas of study of the subjects were similar between treatment and control groups. 307 Indicators for whether a participant was majoring in environmental economics or biology were 308 included because of the potential for effects from their educational program of choice on their 309 decisions.

310 The participants in half of the experimental sessions were exposed to time pressure 311 constraints with a 7-second per round decision time limit. This constraint was chosen because the 312 decision times of subjects within sessions without time pressure indicated that it would be a 313 binding constraint for the majority of them. There was a clock visible to subjects counting down 314 the time and the decision screen disappeared after the 7-second limit was reached. Time pressure 315 was instituted by requiring participants to make extraction decisions within 7 -seconds, and if the 316 time constraint was violated then the participants earned zero tokens (public or private) for that 317 round. When subjects violate the 7-second time limit no tokens are taken from the group account 318 for that subject. To ensure differences in extraction decisions are active choices rather than 319 inaction, 31 out of 2,440 observations where subjects do not make a decision within the time 320 constraint are excluded in the analysis. Similarly, 16 out of 90 groups with a subject who did not 321 enter an extraction decision within the time constraint are excluded from the survival analysis so 322 that any interdependency between that zero-extraction observation and overall survival is not 323 biased. Most participants in sessions without a time constraint took longer to make a decision 324 than the time constraint would have permitted (indicating the 7-second time constraint was 325 binding on average); we find the difference in mean decision time between treatment and control 326 groups is statistically significant at the $1 \%$ level using a Mann-Whitney two sample statistic test. 
We employ a series of statistical tests to estimate the treatment effect of time pressure 328 and the effect of greater CRT scores on cooperative behaviour to understand the cognitive underpinnings of cooperation in a dynamic CPR.

In the model for the dynamic game, the size of the group account (stock) in the present period directly depends on the size of the group stock in the past period and the decisions made by group members in the past period. In our experiment $\beta$ was set at 0.25 and, $\tau$, was set at a stock size of 30 tokens (if the stock size fell below 30 tokens, the group account would not regenerate lost tokens).

There exists a myopic strategy in this game which is the Subgame Perfect Nash Equilibrium (SPNE), wherein each player extracts the maximum amount until the group account is depleted. In the SPNE, forward-looking individual agents consider the trade-off between assured present benefits and uncertain future benefits (measured in terms of tokens extracted from the group account). This SPNE depends on the parameters of the experiment, primarily the relative values of $\beta, \tau$, and $n$. Specifically, when $\beta<\frac{\tau(n-1)}{\bar{w}-\tau}$, or regrowth of the resource is relatively small, there is an SPNE where it is optimal for individuals to exhaust the resource, which is established in the Supplementary Information. Here we demonstrate the SPNEs for our specific parameterization. The level of effort, $e_{i t}$, exerted by individual $i$ at time $t$ is equivalent to

344 the number of group tokens extracted in the experiment. The maximum effort, $\bar{e}$, is the total 345 amount of effort the participant has available to extract from the group account. If $\beta>\frac{\tau(n-1)}{\bar{w}-\tau}$ and $\tau \leq \bar{e}$ the SPNE decision rule is such that we retrieve a set of decision rules that are dependent on the size of the stock in the previous round. The set of decision rules are: choose $e_{i t}=\bar{e}$ if the resource stock is $w_{t-1} \geq n \bar{e}+\tau ; e_{i t}=\frac{w_{t-1}-\tau}{n}$ if $w_{t-1} \in[\tau, n \bar{e}+\tau) ; e_{i t}=\frac{w_{t-1}}{n}$ if $w_{t-1}<\tau ; e_{i t}=\min \left\{\bar{e}, \frac{w_{t-1}}{n}\right\}$ if $w_{t-1}<n \bar{e}+\tau$. These results indicate the symmetric stock specific extraction paths by all participants of a group and mimic the social planner's extraction path. These rules indicate that when the regrowth rate of the stock is relatively high, participants have an incentive to maintain the resource in order to reap the benefits of future periods of the

353 stock and the growth of that stock. When the regrowth rate is relatively small and $\beta<\frac{\tau(n-1)}{\bar{w}-\tau}$ 354 and $\tau \leq \bar{e}$ then the optimal decision rule is to extract $e_{i t}=\min \left\{\bar{e}, \frac{w}{n}\right\}$. This extraction path 355 drives the stock to extinction and is similar to the Nash Equilibrium in the prisoner's dilemma 
game. The proof of the optimal decision rule for our experiment can be found in the

357 Supplementary Notes of our SI. In our parameterization, with a low regrowth rate of the stock,

358 the SPNE decision rule is to extract $e_{i t}=\min \left\{\bar{e}, \frac{w}{n}\right\}$. Though multiple equilibria can exist, 359 invoking the Folk Theorem (41), if subjects are sufficiently patient the SPNE can coincide with 360 the social optimal path of extraction. Through the lens of SHH, the Folk Theorem could 361 operationalize strategic cooperation because individuals can maximize their own payoffs through 362 cooperation. This is true if individuals are patient and expect future gains in later time periods 363 provided others cooperate, as current period cooperative decisions are more likely to sustain later 364 cooperation. For certain values of the parameters $\beta, \tau$, and $n$ the selfish SPNE could also 365 coincide with the socially optimal strategy. For instance, when regrowth of the group account is 366 relatively high the private benefits from cooperating with group members can outweigh the 367 private benefits from extracting the resource to collapse, therefore creating a game where social 368 cooperation and the SPNE are equivalent.

In our experiment, the group account starts with 360 tokens in it and each group token 370 extracted is subtracted from the total amount of tokens in the account. After each round of 371 decision making, the resource stock grows according to the formula $(360-\mathrm{X}) / 4$ tokens, where $\mathrm{X}$ 372 is the stock of group tokens. Therefore, at the beginning of the next period, there will be $\mathrm{X}+$ $373(360-X) / 4$ tokens in the group account. If the total number of tokens in the group account ever 374 falls to fewer than 30 tokens, the threshold $\tau$, the group account will cease to replenish.

376 Econometric Methodology

377 Survival analysis is the appropriate tool to analyse the time to exhaustion of the group account. 378 Ordinary linear regression would require that the group exhaustion times be transformed to 379 account for their strictly positive values and for the censoring of the data. Therefore, survival 380 analysis is more appropriate in our context rather than ordinary linear regression (44).

381 The semi-parametric Cox proportional hazards regression describes the dependence of 382 failure risk at any time, $t$, on the covariates in the regression (41). The Cox model is popular, 383 flexible, and does not assume specific probability distributions until events occur, leading to the 384 advantage of not needing to parameterize time dependency (43). The Cox proportional hazards 385 model is the most commonly used modeling procedure for survival/censored data and covariates. 
In the Cox proportional hazards model, $F(t)$ is the survivor function, $F(t)=\operatorname{Pr}(t \leq T)$ and $\lambda(t)$ is the hazard at time $t$, where $\lambda(t)=\lim _{\Delta t \rightarrow \infty} \frac{\operatorname{Pr}(t \leq T<t+\Delta t \mid T \leq t)}{\Delta t}=f(X \beta)$. We can use a set of $k$ covariates in $X$ and recover the coefficients of vector $\beta$ which tell us about the hazard of failure for a specific covariate. The hazard rate is $\lambda(t \mid X)=\lambda_{0}(t) e^{X \beta}$, where $\beta$ is a $p x 1$ vector of unknown coefficients and $\lambda_{0}(t)$ is an unknown function for the baseline cumulative hazard

391 function when $X=0$. The hazard ratio is thus $\lambda(t) / \lambda_{0}(t)$ and $\ln \left(\frac{\lambda(t)}{\lambda_{0}(t)}\right)=\beta X$. This holds for all 392 individuals so that $\ln \frac{\lambda_{i}(t)}{\lambda_{j}(t)}=\beta\left(X_{j}-X_{i}\right)$ for individuals $i$ and $j$.

In the Cox model, baseline hazard rates vary over time, but the hazards for different covariate values are assumed to be proportional or constant over time. The proportions are also assumed to hold for all periods of $t$ and between all individuals (42). The Cox proportional hazards model implies that an independent variable shifts the hazard by a factor of proportionality. This time invariant proportionality assumption implies that the size of that effect remains the same irrespective of when it occurs. If this assumption is violated, the outcomes can be significantly biased coefficient estimates (and reduced power from significance tests, leading to inefficient estimates) and therefore overestimated or underestimated variable impacts (42).

401 We test for proportionality using Schoenfeld and Deviance residuals and find that for our data the proportionality assumption holds.

We use the Breslow approximation to handle ties in event times. It is the simplest approximation to the probability that an individual had an event, given that an event occurred at that time. While it is the simplest, it also the most conservatively biased (it estimates coefficients too close to zero) and was chosen for such (44). In addition, we cluster standard errors in our analysis by the unit of observation. Observations at the individual subject level can have errors which are correlated and therefore clustering is a common technique for statistical inference of the significance of the recovered coefficients.

411 to the social optimal extraction decision, including a series of controls. The dependent variable

412 is constructed to compare the observed extraction to a stock dependent decision which is deemed 413 cooperative and socially optimal. We define this difference

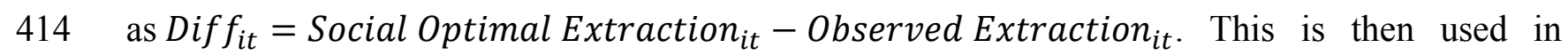
415 equation (1) to evaluate the coefficient on the treatment effect of time pressure. 


$$
\text { Diff }_{i t}=\beta_{0}+\beta_{1} \text { Pressure }_{i}+\beta_{2 \ldots k} X_{i t, 2 \ldots k}+\varepsilon_{i t}
$$

418 Equation 1 includes $k$ covariates to control for other factors that affect decisions such as round in

419 the experiment, gender of the participant, cycle, the experience with economic experiments of

420 participants, undergraduate major, and CRT score. We cluster standard errors in our analysis by

421 subject to adjust for correlation of observations by subject in the experiment. The interpretation

422 of negative coefficient of time pressure is that the effect of the time pressure treatment increased

423 extraction from the group account and participants behaved more selfishly compared to the

424 control group.

\section{Data Availability}

427 The experimental data and code are freely available and have been deposited in figshare at

428 https://doi.org/10.6084/m9.figshare.5965462.v1.

\section{Acknowledgments}

We thank David Rand, Louis Putterman, Antonio Alonso, Steffen Ventz, and Tom Sproul for helpful comments on this work and Carrie Ann Gill for research assistance. This work was supported by the USDA National Institute of Food and Agriculture, Hatch project 1005053 and the RI Water Resources Center.

\section{Ethics} All experiments were conducted at the University of Rhode Island. All procedures, including recruitment, consenting, and testing of human subjects were reviewed and approved by the University of Rhode Island's Institutional Review Board (protocol 476535-6).

442 All authors contributed to the writing of the manuscript. T. Guilfoos and C. Brozyna designed the experiment and analysed the data.

446 The authors declare no competing financial interests.

\section{Corresponding author}

448 Correspondence to T. Guilfoos. 


\section{References}

452 1. Brown, B. J., Hanson, M. E., Liverman, D. M., \& Merideth, R. W. Global sustainability:

453 toward definition. Environmental management. 11(6), 713-719. (1987).

454 2. Pearson, C. S. Down to business: multinational corporations the environment and 455 development. World Resources Institute, Washington, DC. (1985).

456 3. Rand, D. G., Peysakhovich, A., Kraft-Todd, G. T., Newman, G. E., Wurzbacher, O., Nowak,

457 M. A., \& Greene, J. D. Social heuristics shape intuitive cooperation. Nature Communications.

$458 \quad 5: 3677 .(2014)$

459 4. Bear, A., Rand, D. G. Intuition, deliberation, and the evolution of cooperation. PNAS 460 113(4):936-941. (2016).

461 5. Clutton-Brock, T. Cooperation between non-kin in animal societies. Nature 462(7269):51462 57.4. (2009).

463 6. Vollan, B., Ostrom, E. Cooperation and the commons. Science 330(6006):923-924.5. (2010).

464 7. Van Lange, P., Van Vugt, M., De Cremer, D. Choosing between personal comfort and the 465 environment: solutions to the transportation dilemma. Cooperation in Modern Society: 466 Promoting the Welfare of Communities, States and Organizations, eds Van Vugt M, Snyder M, 467 Tyler TR, Biel A (Routledge), pp 45-63. (2012).

468 8. Jentoft, S., Onyango, P., Islam, M. M. Freedom and poverty in the fishery commons. Int $J$ 469 Commons 4(1). doi:10.18352/ijc.157. (2010).

470 9. Ostrom, E. The challenge of common-pool resources. Environment 50(4):8-20,2. (2008).

471 10. Ostrom, E. Governing the commons: the evolution of institutions for collective action

472 (Cambridge University Press, Cambridge, United Kingdom). (1990). 
473 11. Rustagi, D., Engel, S., Kosfeld, M. Conditional cooperation and costly monitoring explain 474 success in forest commons management. Science 330(6006):961-965. (2010).

475 12. Hauser, O. P., Rand, D. G., Peysakhovich, A., Nowak, M. A. Cooperating with the future. 476 Nature 511(7508):220-223. (2014).

477 13. Jabareen, Y. A new conceptual framework for sustainable development. Environment, 478 development and sustainability, 10(2), 179-192. (2008).

479 14. Clark, W. C., \& Dickson, N. M. Sustainability science: the emerging research 480 program. PNAS 100(14): 8059-8061. (2003).

481 15. Lindner, F., Rose, J. No need for more time: intertemporal allocation decisions under time 482 pressure. J Econ Psychol. doi:10.1016/j.joep.2016.12.004. (2016).

483 16. Mani, A., Mullainathan, S., Shafir, E., Zhao, J. Poverty impedes cognitive function. Science 484 341(6149):976-980. (2013).

485 17. Lichand, G., Mani, A. Cognitive Droughts (Competitive Advantage in the Global Economy 486 (CAGE)). (2016).

487 18. Mullainathan, S., Shafir, E. Freeing Up Intelligence. Sci Am Mind 25(1):58-63. (2014).

488 19. Shah, A. K., Mullainathan, S., Shafir, E. Some consequences of having too little. Science 489 338(6107):682-685. (2012).

490 20. Shah, A. K., Shafir, E., Mullainathan, S. Scarcity frames value. Psychol Sci 26(4):402-412. 491 (2015).

492 21. Barrett, C. B., Garg, T., McBride, L. Well-being dynamics and poverty traps. Ann Rev of Res 493 Econ 8(1):303-327. (2016).

494 22. Wright, P. The harassed decision maker: time pressures, distractions, and the use of evidence. 495 J Appl Psychol 59(5):555-561.(1974). 
23. MacGregor, D. Time Pressure and Task Adaptation. Time Pressure and Stress in Human

497 Judgment and Decision Making, eds Svenson O, Maule AJ (Springer US), pp 73-82. (1993).

498 24. Edland, A. The Effects of Time Pressure on Choices and Judgments of Candidates to a

499 University Program. Time Pressure and Stress in Human Judgment and Decision Making, eds

500 Svenson O, Maule AJ (Springer US), pp 145-156. (1993).

501 25. Svenson, O., Benson III, L. Framing and Time Pressure in Decision Making. Time Pressure

502 and Stress in Human Judgment and Decision Making, eds Svenson O, Maule AJ (Springer US),

503 pp 133-144. (1993).

504 26. Sloman, S. A. The empirical case for two systems of reasoning. Psychol Bull 119:3-27. 505 (1996).

506 27. Rand, D. G., Greene, J. D., Nowak, M. A. Spontaneous giving and calculated greed. Nature 507 489(7416):427-430. (2012).

508 28. Rand, D. G., Kraft-Todd, G. T. Reflection does not undermine self-interested prosociality.

509 Front Behav Neurosci 8(Article 300):1-8. (2014).

510 29. Achtziger, A., Alós-Ferrer, C., Wagner, A. Social preferences and Self-Control. (2011).

511 30. Rand, D. G. Cooperation, Fast and Slow: Meta-Analytic Evidence for a Theory of Social 512 Heuristics and Self-Interested Deliberation. Psychol Sci 27(9):1192-1206. (2016).

513 31. Bear, A., Kagan, A., Rand, D. G. Co-evolution of cooperation and cognition: the impact of 514 imperfect deliberation and context-sensitive intuition. Proc R Soc B 284: 20162326. (2017).

515 32. Jagau, S., \& van Veelen, M. A general evolutionary framework for the role of intuition and 516 deliberation in cooperation. Nature Human Behaviour, 1, s41562-017. (2017).

517 33. Goeschl, T., \& Lohse, J. Cooperation in Public Good Games. Calculated or Confused? (No. 518 626). Discussion Paper Series, University of Heidelberg, Department of Economics. (2016). 
519 34. Hahn, M., Lawson, R., Lee, Y. G. The effects of time pressure and information load on 520 decision quality. Psychol Mark 9(5):365-378. (1992).

521 35. Kocher, M. G., Sutter, M. Time is money-Time pressure, incentives, and the quality of 522 decision-making. J Econ Behav Organ 61(3):375-392. (2006).

523 36. Alós-Ferrer, C., Hügelschäfer, S., Li, J. Inertia and Decision Making. Front Psychol 7. 524 doi:10.3389/fpsyg.2016.00169. (2016).

525 37. Janssen, M. Introducing Ecological Dynamics into Common-Pool Resource Experiments. 526 Ecol Soc 15(2). doi:10.5751/ES-03296-150207. (2010).

527 38. Ostrom, E., Gardner, R., Walker, J. Rules, Games, and Common-pool Resources (University 528 of Michigan Press). (1994).

529 39. Kimbrough, E. O., Vostroknutov, A. The social and ecological determinants of common pool 530 resource sustainability. J Environ Econ Manag 72:38-53. (2015).

531 40. Huggett, A. J. The concept and utility of 'ecological thresholds' in biodiversity conservation. 532 Biol Conserv 124(3):301-310. (2005).

533 41. Cox, D. R. Regression Models and Life-Tables. J ROY STAT SOC B 34(2):187-220. (1972).

534 42. Etzioni, R. D., Feuer, E. J., Sullivan, S. D., Lin, D., Hu, C., \& Ramsey, S. D. On the use of 535 survival analysis techniques to estimate medical care costs. $J$ Health Econ 18(3):365-380. 536 (1999).

537 43. Box-Steffensmeier, J. M., Zorn, C. J. W. Duration Models and Proportional Hazards in 538 Political Science. Am J Polit Sci 45(4):972-988. (2001).

539 44. Singer, J. D., Willett, J. B. It's About Time: Using Discrete-Time Survival Analysis to Study 540 Duration and the Timing of Events. J Educ Stat 18(2):155-195. (1993). 
541 45. Fudenberg, D., \& Maskin, E. The Folk Theorem in Repeated Games with Discounting or

542 with Incomplete Information. Econometrica: Journal of the Econometric Society, 533-554.

543 (1986).

544 46. Ostrom, E., Walker, J., \& Gardner, R. Covenants With and Without a Sword: Self545 Governance is Possible. Am Polit Sci Rev 86(2): 404-417. (1992).

546 47. Fischbacher, U. z-Tree: Zurich toolbox for ready-made economic experiments. Exp Econ, 547 10(2): 171-178. (2007).

548 48. Frederick, S. Cognitive Reflection and Decision Making. J Econ Perspect 19(4):25-42.50.

549 (2005).

550 
Table 1: Survival Analysis

Dependent variable:

Failure of Group Account

\begin{tabular}{lccc} 
& $(1)$ & $(2)$ & $(3)$ \\
\hline Pressure & $0.539^{* * *}$ & $0.700^{* * *}$ & $0.788^{* * *}$ \\
Female & $(0.134)$ & $(0.149)$ & $(0.171)$ \\
\# of previous experiments & & 0.214 & $0.334^{* *}$ \\
& & $(0.133)$ & $(0.164)$ \\
UG major: biology & -0.005 & 0.011 \\
& & $(0.084)$ & $(0.085)$ \\
UG major: environmental economics & $-0.412^{* * *}$ & $-0.423^{*}$ \\
Cycle 2 & & $(0.180)$ & $(0.220)$ \\
& & -0.001 & -0.109 \\
Cycle 3 & & $(0.179)$ & $(0.209)$ \\
& & -0.164 & -0.158 \\
\% CRT Correct & & $(0.165)$ & $(0.198)$ \\
& & $-0.540^{* * *}$ & $-0.530^{* *}$ \\
Observations & & $(0.181)$ & $(0.209)$ \\
Log pseudolikelihood & & & $-0.583^{*}$ \\
\hline
\end{tabular}

Note: ${ }^{*} \mathrm{p}<0.1 ;{ }^{* *} \mathrm{p}<0.05 ;{ }^{* * *} \mathrm{p}<0.01$. Cox proportional hazard model results, with stock failure as the event of interest. Clustered standard errors by participant, cycle, and session are in parentheses. Column (1) and (2) contain the full sample of all individuals while column (3) restricts the sample to include only individuals with a CRT score. "UG major:" indicates the participant's area of study. 
Table 2: Extraction Behaviour

Dependent variable:

(SO Extraction - Observed Extraction)

\begin{tabular}{lccc} 
& $(1)$ & $(2)$ & $(3)$ \\
\cline { 2 - 4 } Pressure & -1.079 & $-4.973^{*}$ & $-6.695^{* *}$ \\
Female & $(2.502)$ & $(2.831)$ & $(3.088)$ \\
& & -3.431 & $-6.163^{*}$ \\
\# of previous experiments & & $(2.781)$ & $(3.311)$ \\
& & 1.633 & 1.627 \\
UG major: biology & $(1.633)$ & $(1.555)$ \\
& & 2.269 & 3.509 \\
UG major: environmental economics & $(2.665)$ & $(3.045)$ \\
& & -4.078 & -5.184 \\
Cycle 2 & & $(3.883)$ & $(4.578)$ \\
& & 2.432 & 2.105 \\
Cycle 3 & & $(1.626)$ & $(1.799)$ \\
& & $2.979^{*}$ & 2.443 \\
Round & & $(1.720)$ & $(2.052)$ \\
& & $-1.781^{* * *}$ & $-1.731^{* * *}$ \\
\% CRT Correct & & $(0.196)$ & $(0.231)$ \\
& & & -0.087 \\
Observations & & & $(6.841)$ \\
R-squared & & 1,952 & 1,400 \\
\hline
\end{tabular}

Note: ${ }^{*} \mathrm{p}<0.1 ;{ }^{* *} \mathrm{p}<0.05 ;{ }^{* * *} \mathrm{p}<0.01$. Ordinary least squares regression. Clustered standard errors by participant are in parentheses. Groups with participants who do not enter a decision within the time constraint are excluded from the analysis. Column (1) and (2) contains the full sample of all individuals while column (3) restricts the sample to include only individuals with a CRT score. "UG major:" indicates the participant's area of study. 


\section{Figure 1 Legend}

589 Fig. 1: A graph showing the average size of the group account ( $n=168$ for no time pressure treatment and $n=116$ for 590 the time pressure treatment) at the beginning of each period (the stock size left after the previous period with the 591 addition of regrown stock). The black dashed line indicates the predicted stock sizes were the groups behaving as a 592 social planner would. The blue dashed line indicates the stock path if all the participants are in a competitive 593 Subgame Perfect Nash Equilibrium. 


\section{Tokens in Group Account by Period}

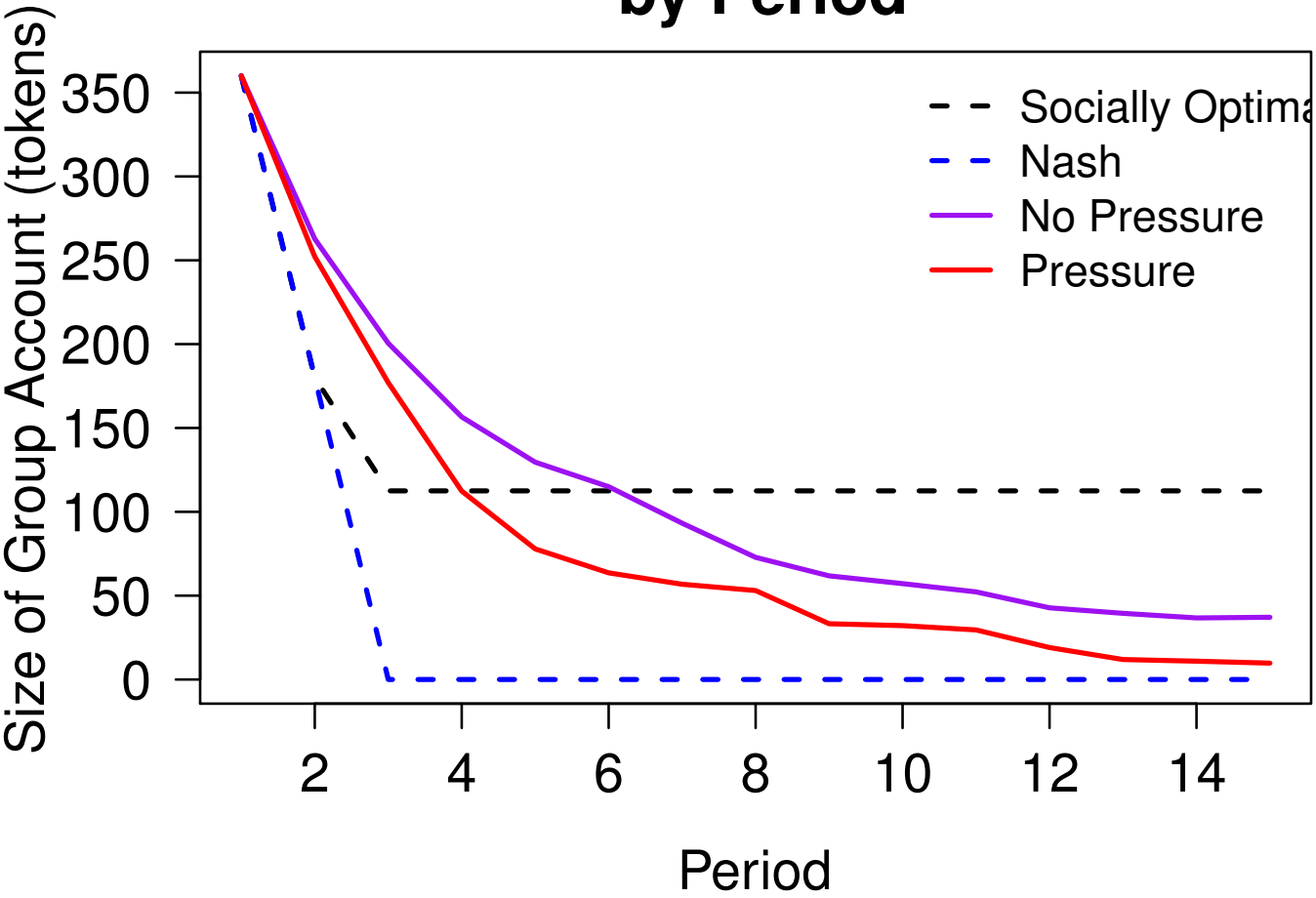

